\title{
Atividades antioxidante, antinociceptiva e anti-inflamatória das folhas de Mucuna pruriens (L.) DC.
}

MOTTA, E.V.S.'; PINTO, N.C.C.'; DUQUE, A.P.N.'; MENDES, R. F.1; BELLOZI, P.M.Q.'; SCIO, E..* Laboratório de Produtos Naturais Bioativos, Instituto de Ciências Biológicas, Universidade Federal de Juiz de Fora, CEP:36036-900, Juiz de Fora-Brasil. *elita.scio@ufff.edu.br

\begin{abstract}
RESUMO: A espécie Mucuna pruriens (L.) DC. (Fabaceae) é popularmente conhecida no Brasil como "café berão" e "pó de mico". Suas sementes são bastante estudadas sendo empregadas na medicina popular para o tratamento de desordens nervosas e do aparelho reprodutor, porém poucas informações sobre a composição química e atividade farmacológica das folhas dessa espécie são descritas na literatura. Assim, os objetivos desse estudo foram: a determinação do perfil fitoquímico, a avaliação da atividade antioxidante in vitro, e a avaliação das atividades anti-inflamatória e antinociceptiva in vivo do extrato metanólico das folhas de $M$. pruriens nas concentrações de 100 e $300 \mathrm{mg} / \mathrm{kg}$. O estudo fitoquímico foi realizado por meio da pesquisa qualitativa dos constituintes químicos e determinação quantitativa do teor de fenóis totais e flavonoides. O potencial antioxidante foi avaliado pelos métodos do DPPH e poder de redução. As atividades anti-inflamatória e antinociceptiva foram a ante foi promissor, com $\mathrm{Cl}_{50}$ de $13,2 \mu \mathrm{g} / \mathrm{mL}$ pelo método do $\mathrm{DPPH}$, e $\mathrm{CE}_{50}$ de $47,9 \mu \mathrm{g} / \mathrm{mL}$ pelo método que avalia o poder de redução. Em relação à atividade anti-inflamatória, o extrato foi capaz de inibir o edema de orelha em $63 \%(100 \mathrm{mg} / \mathrm{kg})$ e $28 \%(300 \mathrm{mg} / \mathrm{kg})$. Quanto à atividade antinociceptiva, houve redução do número de contorções abdominais de $64 \%$ (100 mg/kg) e $69 \%$ (300 mg/kg). Estes resultados indicam que M. pruriens apresenta um potencial farmacológico promissor e reforçam o conceito de que a pesquisa de plantas com usos etnofarmacológicos pode revelar um número substancial de respostas em ensaios in vitro e in vivo.
\end{abstract}

Palavras-chave: Mucuna pruriens, antioxidante, antinociceptivo, anti-inflamatório

ABSTRACT: Antioxidant, antinociceptive and anti-inflammatory activity of Mucuna pruriens (L.) DC. leaves. The species Mucuna pruriens (L.) DC. (Fabaceae) is popularly known in Brazil as "café berão" and "pó de mico". Its seeds have been widely studied and used in folk medicine for the treatment of nervous and reproductive system disorders; however, few studies are related to the chemical composition and pharmacological activity of its leaves. Therefore, the aims of this study were: investigation of the phytochemical profile, in vitro assessment of the antioxidant activity, and in vivo evaluation of the anti-inflammatory and antinociceptive activities of methanol extract of $M$. pruriens leaves at the concentrations of 100 and $300 \mathrm{mg} / \mathrm{kg}$. The phytochemical study was performed by means of qualitative identification of chemical constituents and quantitative determination of total phenols and flavonoids. The antioxidant potential was assayed by DPPH and reducing power methods. Anti-inflammatory and antinociceptive activities were evaluated by croton oil-induced ear edema and acetic acid-induced writhing tests, respectively. Alkaloids, coumarins, flavonoids, triterpenes and saponins were identified in the extract. Total phenol and flavonoid levels were 112 and $18.3 \mathrm{mg} / \mathrm{g}$ extract, respectively. The antioxidant potential was promising, with $\mathrm{IC}_{50}$ of $13.2 \mu \mathrm{g} /$ $\mathrm{mL}$ by DPPH assay and $\mathrm{EC}_{50}$ of $47.9 \mu \mathrm{g} / \mathrm{mL}$ by the method that evaluates the reducing power. Regarding the anti-inflammatory activity, the extract was capable of inhibiting by $63 \%(100 \mathrm{mg} / \mathrm{kg})$ and $28 \%(300 \mathrm{mg} / \mathrm{kg})$ the ear edema. As to the antinociceptive activity, there was a reduction in the number of writhings by $64 \%(100 \mathrm{mg} / \mathrm{kg})$ and $69 \%(300 \mathrm{mg} / \mathrm{kg})$. Results indicate that $\mathrm{M}$. pruriens presents a promising pharmacological potential and reinforce the concept that the investigation of ethnopharmacologically used plants may reveal a substantial number of positive responses in in vitro and in vivo assays.

Keywords: Mucuna pruriens, antioxidant, antinociceptive, anti-inflammatory

Recebido para publicação em 23/05/2012

Aceito para publicação em 03/12/2012

Rev. Bras. PI. Med., Campinas, v.15, n.2, p.264-272, 2013. 


\section{INTRODUÇÃO}

A utilização de plantas com fins medicinais para tratamento, cura e prevenção de doenças, é uma das mais antigas formas de prática medicinal da humanidade. Apesar dos grandes avanços observados na medicina moderna nas últimas décadas, as plantas continuam sendo utilizadas e estima-se que 25 a $30 \%$ de todas as drogas avaliadas como agentes terapêuticos são derivadas de produtos naturais (Newman \& Cragg, 2007). Entretanto, devido à infinidade de espécies vegetais e de substâncias químicas existentes na natureza, não é aconselhável que esses estudos sejam realizados de maneira randômica, pois demandaria muito tempo e as chances de sucesso seriam remotas. Uma abordagem de bioprospecção que tem fornecido resultados promissores é a que se baseia em estudos etnofarmacológicos. Essa abordagem direciona as pesquisas farmacológicas para plantas que já vêm sendo utilizadas popularmente em tratamentos medicinais (Santos, 2006).

Nesse contexto, encontra-se a espécie Mucuna pruriens (L.) DC. (Fabaceae), cujas sementes apresentam propriedades biológicas amplamente estudadas pela medicina tradicional indiana, denominada Ayurveda, bastante difundida pelo mundo (Smit et al., 1995). Essa espécie de feijão é nativa de regiões tropicais, especialmente Índia, África e Ilhas do Pacífico (Rajeshwar et al., 2005). No Brasil, ocorre principalmente nas regiões da Amazônia, Cerrado e Mata Atlântica, sendo conhecida popularmente como café berão e pó de mico (Tozzi et al., 2005). Historicamente, as sementes de $M$. pruriens são utilizadas no tratamento de desordens nervosas, mentais e do aparelho reprodutor, bem como depressão e infertilidade masculina (Tripathi \& Upadhyay, 2002). Alguns estudos demonstraram potencial atividade antioxidante de extratos alcoólicos de sementes de $M$. pruriens (Tripathi \& Upadhyay, 2002; Rajeshwar et at., 2005; Longhi, 2007). Porém, poucas informações sobre a composição química e atividade farmacológica das folhas dessa espécie são descritas na literatura (Salau \& Odeleye, 2007). Dessa forma, esse estudo visa avaliar a atividade antioxidante in vitro do extrato metanólico das folhas de $M$. pruriens e suas atividades anti-inflamatória e antinociceptiva in vivo, além de determinar seu perfil fitoquímico .

\section{MATERIAL E MÉTODOS}

\section{Material Vegetal}

As folhas da espécie vegetal $M$. pruriens foram coletadas em Juiz de Fora, MG, Brasil, em fevereiro de 2010. A exsicata (CESJ 46166) está depositada no Herbário Leopoldo Krieger da Universidade Federal de Juiz de Fora.

\section{Preparo do extrato metanólico}

As folhas de M. pruriens foram coletadas e submetidas à secagem em estufa à $50^{\circ} \mathrm{C}$. O material vegetal seco e estabilizado foi pulverizado e, em seguida, macerado com metanol à temperatura ambiente, até a exaustão. A evaporação do solvente à vácuo em evaporador rotativo resultou no extrato metanólico de M. pruriens (EMP).

\section{Triagem fitoquímica}

EMP foi submetido à triagem fitoquímica preliminar para identificação das principais classes químicas de metabólitos especiais (alcaloides, antraquinonas, compostos fenólicos, cumarinas, esteroides, triterpenos, flavonoides, saponinas e taninos), de acordo com o protocolo descrito por Matos (1997).

\section{Determinação do conteúdo de fenóis totais}

O conteúdo de compostos fenólicos totais no EMP foi determinado pelo método de FolinDenis (Duh \& Yen, 1997). Uma solução estoque em metanol de EMP $(0,5 \mathrm{mg} / \mathrm{mL})$ foi preparada e $1,0 \mathrm{~mL}$ da mesma foi misturada com $1,0 \mathrm{~mL}$ do reagente de Folin-Denis e $8,0 \mathrm{~mL}$ de $\mathrm{Na}_{2} \mathrm{CO}_{3} 2 \%$ em tampão $\mathrm{NaOH} 0,1 \mathrm{~N}$. A mistura foi agitada e após 60 minutos de incubação à $30^{\circ} \mathrm{C}$, foi centrifugada a $3000 \mathrm{rpm}$ por 5 minutos. A absorbância do sobrenadante foi mensurada a $730 \mathrm{~nm}$ em espectrofotômetro. $O$ branco foi preparado com $1,0 \mathrm{~mL}$ de metanol, $1,0 \mathrm{~mL}$ do reagente de Folin-Denis e $8,0 \mathrm{~mL}$ de $\mathrm{Na}_{2} \mathrm{CO}_{3} 2 \%$ em tampão $\mathrm{NaOH}$ 0,1 N. Para a preparação da curva de calibração foram misturados 0,$07 ; 0,10$; 0,$20 ; 0,30 ; 0,40$ e $0,50 \mathrm{~mL}$ de solução de ácido tânico $(1,0 \mathrm{~g} / \mathrm{L})$, controle positivo, completando o volume para $1,0 \mathrm{~mL}$ de etanol. Em seguida, foi realizado o mesmo procedimento descrito para EMP e a curva de calibração foi construída. Todas as determinações foram realizadas em triplicata. $O$ resultado foi expresso em $\mathrm{mg} / \mathrm{g}$ de EMP, em equivalentes de ácido tânico.

\section{Determinação do conteúdo de flavonoides}

O conteúdo de flavonoides no EMP foi determinado pelo método descrito por Miliauskas et al. (2004), com modificações. Uma solução estoque em metanol de EMP $(0,5 \mathrm{mg} / \mathrm{mL})$ foi preparada e 1,0 $\mathrm{mL}$ da mesma foi misturada com $1,0 \mathrm{~mL}$ de $\mathrm{AlCl}_{3}$ $2 \%$ em etanol e 1 gota de ácido acético. $O$ volume foi completado com etanol para $25 \mathrm{~mL}$. Após 40 minutos à temperatura ambiente e ao abrigo da luz, a absorbância foi mensurada a $415 \mathrm{~nm}$. A curva de calibração foi preparada misturando-se 0,1 ;

Rev. Bras. Pl. Med., Campinas, v.15, n.2, p.264-272, 2013. 
0,$25 ; 0,5 ; 1,0$ e $2,0 \mathrm{~mL}$ de uma solução etanólica de rutina $(0,5 \mathrm{mg} / \mathrm{mL})$, controle positivo, com $1,0 \mathrm{~mL}$ de $\mathrm{AlCl}_{3} 2 \%$ em etanol, completando-se o volume para $25 \mathrm{~mL}$ com etanol. Em seguida, foi realizado o mesmo procedimento descrito para EMP e a curva de calibração foi construída. O branco foi preparado com 1,0mL de EMP, 1 gota de ácido acético e o volume completado para $25 \mathrm{~mL}$ com etanol. Todas as determinações foram realizadas em triplicata. $O$ resultado foi expresso em $\mathrm{mg} / \mathrm{g}$ de EMP, em equivalentes de rutina.

\section{Potencial antioxidante DPPH}

A atividade sequestrante de radicais $\mathrm{DPPH}$ foi determinada pelo método descrito por BrandWilliams et al. (1995). Foram transferidos para um poço de uma placa de 96 poços, $100 \mu \mathrm{L}$ de uma solução $1 \mathrm{mg} / \mathrm{mL}$ de EMP. Em seguida, foram realizadas diluições sucessivas 1:2 em metanol e adicionados $150 \mu \mathrm{L}$ de solução de DPPH $20 \mu \mathrm{g} / \mathrm{mL}$ em metanol, obtendo-se as concentrações de 250; $125 ; 62,5 ; 31,2 ; 15,6 ; 7,81 ; 3,92 ; 1,95$ e $0,90 \mu \mathrm{g} /$ $\mathrm{mL}$. A placa foi incubada ao abrigo da luz e após 30 minutos a absorbância foi mensurada a $515 \mathrm{~nm}$. O branco foi preparado da mesma maneira que EMP, utilizando-se metanol no lugar do mesmo. Procedeuse também à medida da absorbância do DPPH sem EMP. Os testes foram realizados em triplicata e a porcentagem (\%) de inibição de oxidação de EMP foi calculada da seguinte maneira:

$\%$ Inibição $=\left[\left(\mathrm{Abs}_{\text {branco }}-\mathrm{Abs}_{\text {amostra }}\right) \div \mathrm{Abs}_{\text {branco }}\right] \times 100$

sendo: $\mathrm{Abs}_{\text {branco }}$ : absorbância mensurada para $\mathrm{o}$ branco;

$\mathrm{Abs}_{\text {amostra }}$ : absorbância mensurada para as amostras.

Foi determinado também a $\mathrm{Cl}_{50}$, concentração de EMP, em $\mu \mathrm{g} / \mathrm{mL}$, que inibe a formação de radicais DPPH em 50\% (RAJESHWAR et al., 2005). $\alpha$-tocoferol, quercetina e rutina foram utilizados como controles positivos. Os dados foram apresentados em comparação com os controles positivos e reportados como a média \pm desvio padrão.

\section{Poder de Redução}

A atividade quelante de metais do EMP foi determinada de acordo com o método descrito por Oyaizu (1986). Uma solução estoque em água destilada de EMP $(1,0 \mathrm{mg} / \mathrm{mL})$ foi preparada e a partir desta foram aliquotados 1000, 500, 250, $125 \mathrm{e}$ $62,5 \mu \mathrm{L}$ em diferentes tubos de ensaio, completando o volume para $1000 \mu \mathrm{L}$ com água destilada. Em cada tubo de ensaio foram adicionados $2,5 \mathrm{~mL}$ de solução tampão fosfato de potássio $(0,2 \mathrm{M}, \mathrm{pH}$
$6,6)$ e $2,5 \mathrm{~mL}$ de solução ferrocianeto de potássio $\left[\mathrm{K}_{3} \mathrm{Fe}(\mathrm{CN})_{6}\right] 1 \%$. A mistura foi incubada à $50^{\circ} \mathrm{C}$ por 20 minutos. Em seguida, foram adicionados $2,5 \mathrm{~mL}$ de solução aquosa de ácido tricloroacético 10\% à mistura, que foi então centrifugada a $3000 \mathrm{rpm}$ por 10 minutos. Foram retirados $2,5 \mathrm{~mL}$ do sobrenadante e adicionados $2,5 \mathrm{~mL}$ de água destilada e $0,5 \mathrm{~mL}$ de solução de cloreto férrico $\left(\mathrm{FeCl}_{3}\right) 0,1 \%$. Ao final deste processo, as seguintes concentrações foram obtidas: 53,$64 ; 26,82 ; 13,41 ; 6,71$ e $3,35 \mu \mathrm{g} / \mathrm{mL}$. A absorbância de cada uma destas concentrações foi mensurada a $700 \mathrm{~nm}$ em espectrofotômetro e em triplicata. Utilizou-se ácido ascórbico $\mathrm{L}(+)$ como controle positivo. O gráfico de absorbância versus concentração foi construído e o valor de $\mathrm{CE}_{50}$ (concentração efetiva que apresenta absorbância igual a 0,5 ) foi estimado de acordo com a curva analítica. Os dados foram apresentados em comparação com o controle positivo e reportados como a média \pm desvio padrão.

\section{Ensaios Farmacológicos Animais}

Os testes foram realizados com camundongos albinos Swiss machos, pesando entre 25 e 35g, provenientes do biotério do Centro de Biologia da Reprodução da Universidade Federal de Juiz de Fora. Os animais foram mantidos em ambiente com temperatura controlada de $23 \pm 2^{\circ} \mathrm{Ce}$ umidade $45-55 \%$, fotoperíodo de 12 horas. Todos os experimentos foram realizados com os animais em jejum de 12 horas, mas com livre acesso a água. Os protocolos utilizados foram aprovados pelo Comitê de Ética na Experimentação Animal (CEEA) desta instituição (protocolo n 009/2009).

\section{Atividade anti-inflamatória - Edema de orelha induzido por óleo de cróton}

A atividade anti-inflamatória foi avaliada pela sua capacidade em inibir a formação do edema na orelha dos animais testados. Para tal, os animais foram divididos em quatro grupos $(n=6)$. O grupo 1 foi tratado com veículo salina 0,9\% (controle negativo); o grupo 2 foi tratado com indometacina $10 \mathrm{mg} / \mathrm{kg}$ (controle positivo); o grupo 3 foi tratado com EMP $100 \mathrm{mg} / \mathrm{kg}$; e o grupo 4 foi tratado com EMP $300 \mathrm{mg} / \mathrm{kg}$. Uma hora após a administração via oral de $10 \mathrm{~mL} / \mathrm{kg}$ do veículo, da indometacina ou de EMP, os animais receberam $20 \mu \mathrm{L}$ de uma solução de óleo de cróton (2,5\%, v/v em acetona) sobre a superfície interna da orelha direita, enquanto a mesma região da orelha esquerda foi tratada com o mesmo volume de acetona. Após 6 horas da aplicação do agente flogístico, os animais foram eutanasiados e discos de $6 \mathrm{~mm}$ de diâmetro foram removidos de cada orelha e pesados. Os resultados foram expressos como a média das diferenças de peso entre as 
orelhas direita e esquerda dos animais em $\mathrm{mg} \pm$ e.p.m., sendo que, quanto menor a diferença de peso, maior o potencial de inibição (Rocha et al., 2008). A porcentagem de inibição do edema foi calculada pela subtração da média dos pesos das orelhas do controle negativo, pela média dos pesos das orelhas do controle positivo ou EMP, dividindose pelo controle negativo e multiplicando-se por 100.

Cabe ressaltar que a solubilização da indometacina foi feita inicialmente com $12 \%$ de Tween 80 . Em seguida foi adicionada solução salina $0,9 \%$ até completar o volume necessário para realização do experimento. Devido a este fato, foi necessário adicionar quantidade proporcional de Tween 80 no veículo e EMP, de modo a manter a homogeneidade das amostras.

\section{Atividade antinociceptiva - Contorções abdominais induzidas por ácido acético}

A atividade antinociceptiva foi avaliada por meio da indução da nocicepção por estímulo químico (ácido acético) em camundongos utilizando-se o método de Koster et al. (1959). Os animais foram divididos em quatro grupos $(n=6)$. O grupo 1 foi tratado com veículo salina $0,9 \%$ (controle negativo); o grupo 2 foi tratado com indometacina $10 \mathrm{mg} / \mathrm{kg}$ (controle positivo); o grupo 3 foi tratado com EMP $100 \mathrm{mg} / \mathrm{kg}$; e o grupo 4 foi tratado com EMP $300 \mathrm{mg} /$ kg. Uma hora após a administração via oral de $10 \mathrm{~mL} /$ $\mathrm{kg}$ do veículo, da indometacina ou de EMP, foi injetado por via intraperitoneal em cada animal, $10 \mathrm{~mL} / \mathrm{kg}$ de ácido acético $0,6 \% \mathrm{v} / \mathrm{v}$ e as contorções abdominais foram contadas durante os 30 minutos subsequentes. Os resultados foram expressos como a média do número de contorções \pm e.p.m. A porcentagem de inibição das contorções abdominais foi calculada pela subtração da média do número de contorções do controle negativo, pela média do número de contorções do controle positivo ou EMP, dividindo-se pelo controle negativo e multiplicando-se por 100.

Neste teste também foi necessário solubilizar a indometacina em $12 \%$ de Tween 80 para depois completar o volume com solução salina $0,9 \%$. Logo, foi adicionada quantidade proporcional de Tween 80 ao veículo e EMP.

\section{Análise estatística}

Nos ensaios biológicos in vitro, foi utilizado o programa Microsoft Office Excel 2007 para o cálculo do conteúdo de fenóis totais e de flavonoides e o programa estatístico Grafit 5 para o cálculo do $\mathrm{Cl}_{50}$ (método do DPPH) e do $\mathrm{CE}_{50}$ (poder de redução). Já para os ensaios biológicos in vivo, foi utilizado o programa estatístico GraphPad Prism 5 para as análises de variância (ANOVA) seguidas pelo teste de Newman-Keuls como post-hoc, com grau de significância de $5 \%$.

\section{RESULTADOS}

Triagem fitoquímica

Os resultados da triagem fitoquímica estão representados na Tabela 1.

\section{Determinação do conteúdo de fenóis totais e flavonoides}

EMP apresentou $112 \pm 9,4 \mathrm{mg}$ de fenóis $/ \mathrm{g}$ de extrato em equivalentes de ácido tânico e 18,3 \pm $1,8 \mathrm{mg}$ de flavonoides/g de extrato em equivalentes de rutina.

\section{Potencial antioxidante}

Os resultados da atividade antioxidante do EMP frente aos métodos DPPH e Poder de Redução encontram-se na Tabela 2.

\section{Ensaios farmacológicos \\ Atividade anti-inflamatória - Edema de orelha induzido por óleo de cróton \\ $O$ efeito anti-inflamatório do EMP nas concentrações de 100 e $300 \mathrm{mg} / \mathrm{kg}$ e da indometacina está representado pela Figura 1. Os percentuais de}

TABELA 1. Constituintes químicos do extrato metanólico das folhas de Mucuna pruriens

\begin{tabular}{lc}
\hline Classes de constituintes químicos & Resultados $^{\mathrm{a}}$ \\
\hline Compostos fenólicos & + \\
Flavonoides & + \\
Taninos & - \\
Cumarinas & + \\
Saponinas & + \\
Esteroides & - \\
Triterpenos & + \\
Antraquinonas & - \\
Alcaloides & + \\
\hline
\end{tabular}

a presença (+) ou ausência (-)

TABELA 2: Atividade antioxidante do extrato metanólico das folhas de Mucuna pruriens (EMP) pelos métodos do DPPH e Poder de Redução

\begin{tabular}{lcc}
\hline Amostras & $\begin{array}{c}\text { DPPH }-\mathrm{Cl}_{50} \\
(\mu \mathrm{g} / \mathrm{mL})^{\mathrm{a}}\end{array}$ & $\begin{array}{c}\text { Poder de Redução } \\
-\mathrm{CE}_{50}(\mu \mathrm{g} / \mathrm{mL})^{\mathrm{a}}\end{array}$ \\
\hline EMP & $13,2 \pm 1,20$ & $47,9 \pm 0,01$ \\
-tocoferol $^{\mathrm{b}}$ & $4,14 \pm 0,57$ & - \\
Quercetina $^{\mathrm{b}}$ & $2,50 \pm 0,60$ & - \\
Rutina $^{\mathrm{b}}$ & $0,98 \pm 0,20$ & - \\
Ácido ascórbico $^{\mathrm{b}}$ & - & $2,39 \pm 0,05$
\end{tabular}

${ }^{a}$ Médias dos ensaios em triplicata \pm desvio padrão. ${ }^{b}$ Controles positivos. 
inibição do edema de orelha, em relação ao controle negativo, encontram-se na Tabela 3.

\section{Atividade antinociceptiva - Contorções abdominais induzidas por ácido acético \\ $O$ efeito antinociceptivo do EMP nas} concentrações de 100 e $300 \mathrm{mg} / \mathrm{kg}$ e da indometacina está representado pela Figura 2. Os percentuais de inibição das contorções abdominais, em relação ao controle negativo, encontram-se na Tabela 4.
TABELA 3: Porcentagem de inibição do edema de orelha induzido pelo óleo de cróton causada pelo extrato metanólico das folhas de Mucuna pruriens em camundongos

\begin{tabular}{lc}
\hline Administrações & \% inibição do edema \\
\hline Veículo & 0 \\
Indometacina $10 \mathrm{mg} / \mathrm{kg}$ & 87 \\
EMP $100 \mathrm{mg} / \mathrm{kg}$ & 63 \\
EMP $300 \mathrm{mg} / \mathrm{kg}$ & 28
\end{tabular}

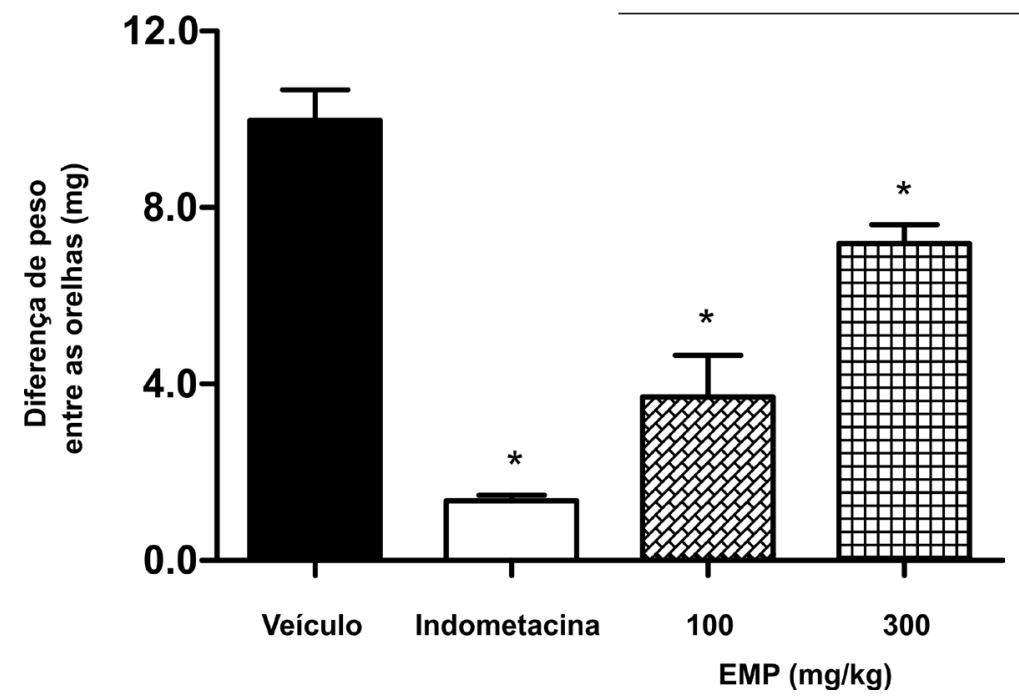

FIGURA 1. Efeito do extrato metanólico das folhas de Mucuna pruriens (EMP) e indometacina via oral sobre o estímulo inflamatório induzido pelo óleo de cróton em camundongos $(n=6)$. Controle negativo (veículo), indometacina $(10 \mathrm{mg} / \mathrm{kg}$ ) e EMP $100 \mathrm{mg} / \mathrm{kg}$ e $300 \mathrm{mg} / \mathrm{kg}$ foram administrados 60 minutos antes da aplicação tópica de óleo de cróton $2,5 \%(\mathrm{v} / \mathrm{v})$. Os valores em cada coluna representam a média \pm e.p.m. da diferença de peso entre as orelhas (mg). Foi realizado o teste ANOVA, seguido pelo teste de Newman-Keuls. Valores significativos: $P^{\star}<0,05$ versus veículo.

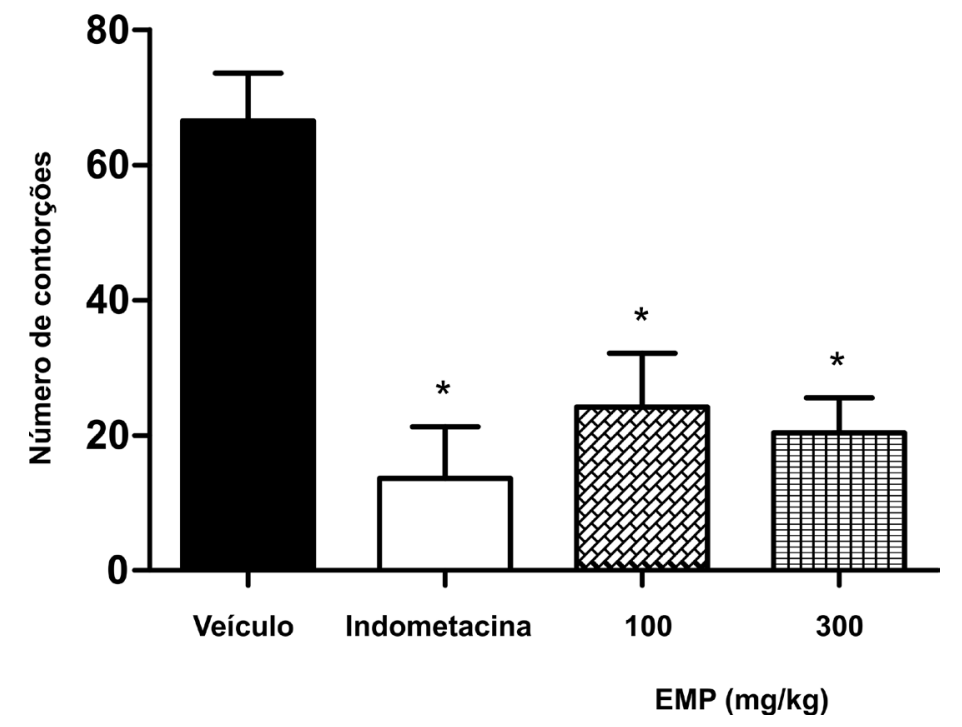

FIGURA 2. Efeito do extrato metanólico das folhas de Mucuna pruriens (EMP) e da indometacina via oral sobre as contorções abdominais induzidas por ácido acético em camundongos $(n=6)$. Controle negativo (veículo), indometacina $(10 \mathrm{mg} / \mathrm{kg}$ ) e EMP $(100$ e $300 \mathrm{mg} / \mathrm{kg}$ ) foram administrados 60 minutos antes da injeção intraperitoneal de ácido acético $0,6 \%$ (v/v) e o número de contorções abdominais foi avaliado durante 30 minutos. Os valores em cada coluna representam a média \pm e.p.m. do número de contorções abdominais. Foi realizado o teste ANOVA, seguido pelo teste de Newman-Keuls. Valores significativos: $P^{*}<0,05$ versus veículo. 
TABELA 4: Efeito do extrato metanólico das folhas de Mucuna pruriens sobre as contorções abdominais induzidas por ácido acético em camundongos

\begin{tabular}{lc}
\hline Administrações & $\begin{array}{c}\text { \% inibição do no de } \\
\text { contorções abdominais }\end{array}$ \\
\hline Veículo & 0 \\
Indometacina 10mg/kg & 79 \\
EMP 100mg/kg & 64 \\
EMP 300mg/kg & 69 \\
\hline
\end{tabular}

\section{DISCUSSÃO}

A triagem fitoquímica teve como objetivo identificar as principais classes de constituintes químicos presentes em EMP. Como pode ser observado na Tabela 1, EMP revelou a presença de substâncias fenólicas, flavonoides, alcaloides, cumarinas, triterpenos e saponinas. Uma vez constatada a presença de compostos fenólicos, tais como flavonoides e, sabendo-se da correlação destes com o potencial antioxidante que uma espécie vegetal pode apresentar, procedeu-se à quantificação do conteúdo de fenóis totais e flavonoides. Os resultados obtidos foram significativos quando comparados com dados descritos na literatura para as sementes da mesma espécie (LONGHI, 2007). Para a determinação da atividade antioxidante foram utilizados métodos espectrofotométricos. O método descrito por Brand-Williams et al. (1995) é baseado na captura do radical DPPH por antioxidantes, produzindo um decréscimo da absorbância a 515 $\mathrm{nm}$. O DPPH é um radical estável, de coloração púrpura. Na presença de substâncias antioxidantes, ele recebe $\mathrm{H}^{+}$sendo então reduzido e, com isso, passa a apresentar coloração amarela. EMP apresentou, por esse método, $\mathrm{Cl}_{50}$ de 13,2 $\pm 1,20 \mu \mathrm{g} /$ $\mathrm{mL}$, enquanto os controles positivos $\alpha$-tocoferol, quercetina e rutina apresentaram $\mathrm{Cl}_{50}$ de 4,14 \pm $0,57 \mu \mathrm{g} / \mathrm{mL}, 2,50 \pm 0,60 \mu \mathrm{g} / \mathrm{mL}$ e $0,98 \pm 0,20 \mu \mathrm{g} / \mathrm{mL}$, respectivamente (Tabela 1). Existem muitos dados sobre os efeitos antioxidantes de diversos grupos de compostos polifenólicos presentes nos extratos de plantas, como flavonoides, taninos, catequinas, proantocianidinas e alguns ácidos polifenólicos (Van Acker et al., 1996). Os polifenóis de origem natural, particularmente os flavonoides, possuem a capacidade de captação de radicais livres sendo que a atividade antioxidante de alguns deles pode superar o efeito de antioxidantes conhecidos, como as vitaminas A e E (Rice-Evans, Miller \& Paganga, 1996).

O método que avalia o poder de redução de íons ferro indica a capacidade de uma substância em doar elétrons e, consequentemente, reduzir os intermediários oxidados por processos de peroxidação lipídica (Oyaizu, 1986). Nesse caso, EMP apresentou $\mathrm{CE}_{50}$ de $47,9 \pm 0,01 \mu \mathrm{g} / \mathrm{mL}$, enquanto o valor encontrado para o ácido ascórbico foi de 2,39 $\pm 0,05 \mu \mathrm{g} / \mathrm{mL}$. Dessa forma, é possível afirmar que EMP apresenta substâncias doadoras de elétrons e prótons, capazes de neutralizar radicais livres e torná-los produtos mais estáveis e também capazes de reduzir intermediários oxidativos dos processos de peroxidação lipídica. Apesar de não ser possível inferir com precisão quais são os compostos responsáveis pela ação antioxidante do EMP, os flavonoides devem ser parcialmente responsáveis por esta atividade, tendo em vista os inúmeros trabalhos que relatam as diferentes atividades exibidas por esta classe de compostos, os quais são descritos preponderantemente como potentes antioxidantes (Alves et al., 2007).

O potencial antioxidante e o teor de fenólicos totais e flavonoides também podem ser úteis para promover outras investigações e correlacionar esta atividade a outras importantes, como, por exemplo, à atividade anti-inflamatória. Vários trabalhos na literatura sugerem a correlação entre as atividades antioxidante e anti-inflamatória, ou seja, alguns extratos vegetais reduzem inflamações por eliminar superóxidos conhecidos por participarem do recrutamento de células polimorfonucleares presentes em tecidos inflamados (Thambi et al., 2009).

O modelo utilizado para avaliação da atividade anti-inflamatória por meio da indução de edema de orelha teve o óleo de cróton como agente flogístico. Esse modelo permite avaliar a atividade de agentes anti-inflamatórios esteroidais ou não esteroidais de administração sistêmica, assim como de uso tópico (Schiantarelli et al., 1982). O principal agente irritante que compõe o óleo de cróton é o acetato de tetradecainol-forbol (TPA), cuja ação é exercida por produtos da cicloxigenase, histamina e serotonina, dentre outros mediadores (Saraiva et al., 2010). Há indução da inflamação cutânea e hiperproliferação celular em animais. Dessa maneira, o modelo tem importância na descoberta de novos produtos farmacêuticos para serem utilizados no tratamento de doenças de pele (Boller, 2007).

Considerando-se a formação do edema como parâmetro de avaliação da intensidade do processo inflamatório, a aplicação tópica de óleo de cróton induz a uma resposta inflamatória aguda, caracterizada por edema, infiltração de neutrófilos, produção de prostaglandinas e leucotrienos e aumento da permeabilidade vascular. O edema se forma, principalmente, pela atividade de eventos vasculares do processo inflamatório, como a vasodilatação e o aumento da permeabilidade vascular, com extravasamento de proteínas e, 
consequentemente, de água para manutenção da pressão oncótica local. A produção do edema se deve inicialmente a histamina e serotonina e, posteriormente, a síntese de prostaglandinas e leucotrienos, sendo as atividades pró-inflamatórias deste óleo dependentes, em sua maior parte, da formação do ácido araquidônico. Dessa forma, tanto os inibidores da fosfolipase A2, como das vias das cicloxigenases ou lipoxigenases, assim como os corticosteroides, são efetivos na supressão do edema de orelha (Zhang et al., 2007).

Os anti-inflamatórios não esteroidais, como a indometacina, são fármacos muito empregados para aliviar a dor de intensidades e tempos variáveis, contudo, como qualquer medicamento, requerem cuidados na sua prescrição e utilização. Possuem potente atividade analgésica e anti-inflamatória, inibindo a transmissão nociceptiva, além da prevenção do edema e da inflamação (Steagall et al., 2009). Pode-se dizer que ainda não dispomos de um fármaco anti-inflamatório e antinociceptivo ideal. Embora altamente eficazes, os analgésicos de ação central não podem ser dissociados de efeitos adversos importantes. E os analgésicos de ação periférica têm seu uso limitado devido a propriedades inerentes frequentemente não dissociáveis de efeitos indesejáveis tais como lesões do trato gastrointestinal e renal (Ferreira, 1993).

Analisando os resultados obtidos, pode-se afirmar que EMP apresentou considerável atividade anti-inflamatória na concentração de 100 mg/ $\mathrm{kg}$ quando comparado à indometacina (Figura 1, Tabela 3). Essa atividade pode estar relacionada com a inibição de alguns mediadores químicos da inflamação, como leucotrienos e endoperóxidos (prostaglandinas, prostaciclinas e tromboxanas), ou pela ação inibitória sobre a enzima fosfolipase A2 (Carvalho \& Lemônica, 1998). Já na concentração de $300 \mathrm{mg} / \mathrm{kg}$, os valores encontrados para EMP e controle negativo foram significativamente diferentes, assim como os valores encontrados para EMP e controle positivo, indicando que houve redução do processo inflamatório, mas não tão eficiente quanto comparado à indometacina. Para o ensaio farmacológico em questão, esse fato sugere que EMP apresenta um potencial anti-inflamatório sistêmico que atuaria em doses mais baixas, para o qual estudos futuros são necessários. Muitos medicamentos têm efeito dose-dependente, o que indica que acima de certa concentração de administração o efeito decai ou é prejudicial. O paracetamol, por exemplo, é um analgésico e antipirético que em doses acima de $1000 \mathrm{mg}$ pode induzir asma, urticária ou complicações hepáticas. Além disso, os próprios anti-inflamatórios não esteroidais são excelentes analgésicos e antipiréticos em baixas doses (Soares et al., 2006).
A atividade antinociceptiva do EMP foi avaliada pelo teste de contorções abdominais induzidas por ácido acético. Nesse modelo, ocorre indução de contração e rotação do abdômen dos camundongos, seguida pela extensão de uma ou ambas as patas traseiras (Koster et al., 1959). O ácido acético, agente utilizado para estímulo da nocicepção, quando injetado por via intraperitoneal, induz às contorções abdominais através de uma ação indireta, por meio da liberação de mediadores endógenos, que estimulam os neurônios nociceptivos sensíveis tantos aos anti-inflamatórios quanto aos analgésicos opióides (Fischer et al., 2008). A sensibilização de nociceptores ocorre por liberação e/ou produção de mediadores como histamina, serotonina, bradicinina, citocinas, óxido nítrico e, principalmente, das prostaglandinas. Esse modelo de nocicepção também induz a liberação de TNF- $\alpha$ e IL-1 $\beta$, sendo demonstrado que os anticorpos contra esses mediadores inibem as contorções abdominais. Outro componente importante da dor produzida nesse modelo são as quimiocinas, que medeiam a participação do simpático na atividade analgésica observada (Verri et al., 2006). Entretanto, as prostaglandinas são os mediadores inflamatórios mais importantes para causar a hiperalgesia, por tornar as fibras aferentes nociceptivas potencialmente sensível aos diversos mediadores (Santos et al., 1998), resultando no comportamento das contorções abdominais dos animais.

Este teste é considerado inespecífico, porém útil em triagem de substâncias analgésicas, independentemente do seu modo de ação. Assim, trata-se de um modelo de triagem sensível a substâncias analgésicas de ação central e/ou periférica dotadas dos mais variados mecanismos de ação, útil para avaliar a analgesia moderada produzida por compostos anti-inflamatórios (Duarte, Nakamura \& Ferreira, 1987; Dickenson \& Ghandehari, 2007).

Os resultados do teste de contorções abdominais induzidas por ácido acético demonstraram que o EMP apresentou significativa atividade antinociceptiva em ambas as concentrações testadas quando comparada com a indometacina (Figura 2, Tabela 4). Atividades anti-inflamatória e antinociceptiva de extratos vegetais têm sido atribuídas principalmente a substâncias flavonoídicas (Kim et al., 2004), as quais são potentes inibidores da enzima óxido nítrico sintase tipo 2, responsável pela síntese de óxido nítrico (NO), que indiretamente bloqueiam as vias da cicloxigenase e/ou lipoxigenase (Robak et al., 1998) e da proteína quinase C e L-arginina/NO (Meotti et al., 2006). Essas vias têm sido implicadas em uma série de eventos moleculares envolvidos 
nas atividades anti-inflamatória (KIM et al., 2004) e antinociceptiva (Machelska et al., 1997). Além disso, os flavonoides são capazes de inibir a fosfolipase A2 e a fosfolipase C, enzimas importantes da cascata de mediadores dos processos inflamatórios (Middleton et al, 2000).

\section{CONCLUSÃO}

Considerando que substâncias naturais podem ser responsáveis pelo efeito de proteção contra os riscos de muitos processos patológicos, os resultados descritos neste estudo demonstram que a espécie $M$. pruriens se apresenta como uma fonte promissora de substâncias com atividades antioxidante, anti-inflamatória e antinociceptiva.

\section{AGRADECIMENTOS}

Os autores agradecem a Fundação de Amparo à Pesquisa do Estado de Minas Gerais (FAPEMIG) e a Universidade Federal de Juiz de Fora (UFJF) pelo apoio financeiro, ao Centro de Biologia da Reprodução (CBR) da UFJF pelo fornecimento dos animais, à Dra. Fátima Regina Salimena pela identificação botânica da espécie vegetal e ao Delfino Antônio Campos pela assistência técnica.

\section{REFERÊNCIA}

ALVES, C. Q.; BRANDÃO, H. N.; DAVID, J. M.; DAVID, J. P.; LIMA, L. S. Avaliação da atividade antioxidante de flavonóides. Diálogos e Ciência - Revista da Rede de Ensino FTC, v. 5, n. 12, p. 1-8, 2007.

BOLLER, S. Atividade antiinflamatória tópica do extrato e compostos isolados da Baccharis illinita DC. (Asteraceae) em camundongos. 2007. 69 p. Dissertação (Mestrado em Farmacologia) - Setor de Ciências Biológicas, Universidade Federal do Paraná, Curitiba.

BRAND-WILLIAMS, W.; CUVELIER, M. E.; BERSET, C. Use of a free radical method to evaluate antioxidant activity. Food Science and Technology, v. 28, n. 1, p. 25-30, 1995.

CARVALHO, W. A.; LEMÔNICA, L. Mecanismos celulares e moleculares da dor inflamatória. Modulação periférica e avanços terapêuticos. Revista Brasileira de Anestesiologia, Rio de Janeiro, v. 48, n. 2, p. 137-58, 1998.

DICKENSON, A. H.; GHANDEHARI, J. Anti-convulsants and anti-depressants. In: STEIN, C. Handbook of experimental pharmacology: analgesia. Berlin: Springer, 2007. v. 177, p. 145-77.

DUARTE, I. D.; NAKAMURA, M.; FERREIRA, S. H. Participation of the sympathetic system in acetic acidinduced writhing in mice. Brazilian Journal of Medical Biological Research, v. 21, n. 2, p. 341-43, 1987.

DUH, P.-D.; YEN, G.-C. Antioxidative activity of three herbal water extracts. Food Chemistry, v. 60, n. 4, p. 639-45, 1997.
FERREIRA, S. H. The role of interleukins and nitric oxide in the mediation of inflammatory pain and its control by peripheral analgesics. Drugs, v. 46, n. 1, p. 1-9, 1993. FISCHER, L. G.; SANTOS, D.; SERAFIN, C.; MALHEIROS, A.; DELLE MONACHE, F.; DELLE MONACHE, G.; CECHINEL FILHO, V.; SOUZA, M. M. Further antinociceptive properties of extracts and phenolic compounds from Plinia glomerata (Myrtaceae) leaves. Biological and Pharmaceutical Bulletin, v. 31, n. 2, p. 235-39, 2008.

KIM, H. P.; SON, K. H.; CHANG, H. W.; KANG, S. S. Anti-inflammatory plant flavonoides and cellular action mechanisms. Journal of Pharmacological Sciences, v. 96, n. 3, p. 229-45, 2004.

KOSTER, R; ANDERSON, M.; BEER, E. J. Acetic acid for analgesic screening. Federation Proceedings, $v$. 18, p. 412-21, 1959.

LONGHI, J. G. Atividade biológica da semente de Mucuna pruriens. 2007. 66 p. Dissertação (Mestrado em Ciências farmacêuticas) - Setor de Ciências da Saúde, Universidade Federal do Paraná, Curitiba.

MACHELSKA, H.; LABUZ, D.; PRZEWLOCKI, R.; PRZEWLOCKA, B. Inhibition of nitric oxide synthase enhances antinociception mediated by mu, delta and kappa opioid receptors in acute and prolonged pain in the rat spinal cord. Journal of Pharmacology and Experimental Therapeutics, v. 282, n. 2, p. 977-84, 1997.

MATOS, F. J. A. Introdução à fitoquímica experimental. Fortaleza: Edições UFC, 1997.

MEOTTI, F. C.; LUIZ, A. P.; PIZZOLATTI, M. G.; KASSUYA, C. A. L.; CALIXTO, J. B.; SANTOS, A. R. S. Analysis of the antinociceptive effect of the flavonoid myricitrin: evidence for a role of the L-arginine-nitric oxide and protein kinase $C$ pathways. Journal of Pharmacology and Experimental Therapeutics, v. 316, n. 2, p. 78996, 2006.

MIDDLETON, E. J..; KANDASWAMI, C.; THEOHARIDES, T. C. The effects of plant flavonoids on mammalian cells: implications for inflammation, heart disease, and cancer. Pharmacological Reviews v. 52, n. 4, p. 673-751, 2000.

MILIAUSKAS, G.; VENSKUTONIS, P. R.; VAN BEEK, T. A. Screening of radical scavenging activity of some medicinal and plant extracts. Food Chemistry, v. 85, n. 2, p. 231-37, 2004

NEWMAN, D. J.; CRAGG, G. M. Natural products as sources of new drugs over the last 25 years. Journal of Natural Products, v. 70, n. 3, p. 461-77, 2007.

OYAIZU, M. Studies on products of the browning reaction. Antioxidative activities of browning reaction products prepared from glucosamine. Japanese Journal of Nutrition, v. 44, n. 6, p. 307-15, 1986.

RAJESHWAR, Y.; KUMAR, S.; GUPTA, M.; MAZUMDER, $U$. K. Studies on in vitro antioxidant activities of methanol extract of Mucuna pruriens (Fabaceae) seeds. European Bulletin of Drug Research, v. 13, n. 1, p. 31-9, 2005.

RICE-EVANS, C.; MILLER, N. J.; PAGANGA, G. Structureantioxidant activity relationships of flavonoids and phenolic acids. Free Radical Biology and Medicine, v. 20, n. 7, p. 933- 56, 1996.

ROBAK, J.; SHRIDI, F.; WOLBIS, M.; KROLIKOWSKA, M. Screening of the influence of flavonoids on lipoxygenase and cyclooxygenase activity, as well as on nonenzymic

Rev. Bras. PI. Med., Campinas, v.15, n.2, p.264-272, 2013. 
lipid oxidation. Polish Journal of Pharmacology and Pharmacy, v. 40, n. 5, p. 451-58, 1998.

ROCHA, F. F.; NEVES, E. M. N.; COSTA, E. A.; MATOS, L. G.; MÜLLER, A. H.; GUILHON, G. M. S. P.; CORTES, W. S.; VANDERLINDE, F. A. Evaluation of antinociceptive and antiinflammatory effects of Croton pullei var. glabrior Lanj. (Euphorbiaceae). Revista Brasileira de Farmacognosia, v. 18, n. 3, p. 344-49, 2008.

SALAU, A. O.; ODELEYE, O. M. Antimicrobial activity of Mucuna pruriens on selected bactéria. African Journal of Biotechnology, v. 6, n. 18, p. 2091-92, 2007.

SANTOS, A. R. S.; VEDANA, E. M. A.; FREITAS, G. A. $G$. Antinociceptive effects of meloxicam, in neurogenic and inflammatory nociceptive models in mice. Inflammation Research, v. 47, n. 7, p. 302-7, 1998.

SANTOS, F. V. Avaliação da mutagenicidade in vivo e in vitro de compostos obtidos de plantas nativas do cerrado. 2006. 152 p. Tese (Doutorado em Análises Clínicas) - Faculdade de Ciências Farmacêuticas, Universidade Estadual de São Paulo, Araraquara.

SARAIVA, R. A.; ARARUNA, M. K. A.; OLIVEIRA, R. C.; MENEZES, K. D. P.; LEITE, G. O.; KERNTOPF, M. F.; COSTA, J. G. M.; ROCHA, J. B. T.; TOMÉ, A. R.; CAMPOS, A. R.; MENEZES, I. R. A. Topical antiinûammatory effect of Caryocar coriaceum Wittm. (Caryocaraceae) fruit pulp ûxed oil on mice ear edema induced by different irritant agents. Journal of Ethnopharmacology, v. 136, n. 3, p. 504-10, 2010.

SCHIANTARELLI, P.; CADEL, S.; ACERBI, D.; PAVESI, L. Antiinflamatory activity and bioavailability of percutaneous piroxican. Arzneimittel Forschung I Drug Research, v. 32, n. 3, p. 230-35, 1982.

SMIT, H. F.; WOERDENBAG, H. J.; SINGH, R. H.; MEULENBELD, G. J.; LABADIE, R. P.; ZWAVING, J. H. Ayurvedic herbal drugs with possible cytostatic activity. Journal of Ethnopharmacology, v. 47, n. 2, p. 75-84, 1995.

SOARES, C. L. S.; PÉREZ, C. D.; MAIA, M. B. S.;
SILVA, R. S.; MELO, L. F. A. Avaliação da atividade antiinflamatória e analgésica do extrato bruto hidroalcoólico do zoantídeo Palythoa caribaeorum (Duchassaing \& Michelotti, 1860). Revista Brasileira de Farmacognosia, v. 16, n. 4, p. 463-68, 2006.

STEAGALL, P. V.; MOUTINHO, F. Q.; MANTOVANI, F. B.; PASSARELLI, D.; THOMASSIAN, A. Evaluation of the adverse effects of subcutaneous carprofen over six days in healthy cats. Research in Veterinary Science, v. 86, n. 1, p. 115-20, 2009.

THAMBI, P. T.; KUZHIVELIL, B.; SABU, M. C.; JOLLY, C. I. Antioxidant and anti-inflammatory activities of the flowers of Tabernaemontana coronaria (L) R. Br. Indian Journal of Pharmaceutical Sciences, v. 68, n. 3, p. 352-55, 2006.

TOZZI, A. M. G. A.; AGOSTINI, K.; SAZIMA, M. A new species of Mucuna Adans. (Leguminosae, Papilionoideae, Phaseoleae) from southeastern Brazil, with a key to Brazilian species. Taxon, v. 54, n. 2, p. 451-55, 2005.

TRIPATHI, Y. B., UPADHYAY, A. K. Effect of the alcohol extract of the seeds of Mucuna pruriens on free radicals and oxidative stress in albino rats. Phytotherapy Research, v. 16, n. 6, p. 534-38, 2002.

VAN ACKER, S. A. B. E.; VAN DEN BERG, D. J.; TROMP, M. N. J. L.; GRIFFIOEN, D. H.; VAN BENNEKOM, W. P.; VADER VIJGH, W. J. F.; BAST, A. Structural aspects of antioxidant activity of flavonoids. Free Radical Biology and Medicine, v. 20, n. 3, p. 331-42, 1996.

VERRI, W. A. J.; CUNHA, T. M.; PARADA, C. A.; POOLE, S.; CUNHA, F. Q.; FERREIRA, S. H. Hypernociceptive role of cytokines and chemokines: targets for analgesic drug development? Pharmacology and Therapeutics, v. 112, n. 1, p. 116-38, 2006.

ZHANG, B.; LI, J. B.; ZHANG, D. M.; DING, Y.; DU, G. H. Analgesic and anti-inflammatory activities of a fraction rich in gaultherin isolated from Gaultheria yunnanensis (FRANCH.) REHDER. Biological and Pharmaceutical Bulletin, v. 30, n. 3, p. 465-69, 2007. 